\title{
Vitiligo and Chronic Photosensitivity in Human Immunodeficiency Virus Infection
}

\author{
Naoko TOJO, Nobuyuki Yoshimura, Masafumi YoshizAwa, Masahiko ICHIOKA, \\ Mamoru CHIDA, Itsurou MiYAZATo, Satoshi TANIAI, Fumiaki MaRumo, \\ Osamu MATUBARA*, Takurou KATO**, Rinko OOTAKI** and Tetsuo SHIOHARA***
}

\begin{abstract}
A 56-year-old man was admitted with hemiparesis and shortness of breath. He was positive to human immunodeficiency virus (HIV) antibody and was diagnosed as acquired immunodeficiency syndrome (AIDS) with Kaposi's sarcoma and pneumocystis carinii pneumonia. He developed chronic photosensitivity and vitiligo preceding the onset of the AIDS-related complex (ARC). Association of the two skin lesions with HIV infection is very rare. Although the role of HIV infection in these skin lesions is not significant, the immunological responses in the early course of $\mathrm{HIV}$ infection may have contributed to the development of both of these skin lesions.
\end{abstract}

Key words: AIDS, Kaposi's sarcoma, Pneumocystis carinii

Most patients infected with human immunodeficiency virus (HIV) develop dermatologic manifestations with progression of their disease. A variety of cutaneous complications have been associated with HIV infection, including opportunistic infections, psoriasis, and seborrheic dermatitis, as well as neoplastic lesions like Kaposi's sarcoma. Here we report a case of an HIV-infected patient who developed, prior to the onset of acquired immunodeficiency syndrome (AIDS), vitiligo and chronic photosensitivity, both of which may be related to autoimmunity. The coincidence of these skin lesions in the early phase and their subsequent regression in the immunodeficient state suggests that certain immunological responses might be induced by HIV infection in the early course of this case.

\section{CASE}

A 56-year-old man was admitted to Tokyo Medical and Dental University Hospital on January
25, 1989 because of hemiparesis, shortness of breath, and slight fever.

$\mathrm{He}$ had a history of pleuritis at age 20 , and malaria at age 50 . He had no history of drug abuse or blood transfusions. He resided in Zaire from October 1982 to September 1986 due to his business. In March 1985 he began to suffer from itching, pruritic scaling, and erythema that appeared on the head, face, neck, and both arms and hands. Laboratory data at that time revealed $\gamma$-GTP 66 $\mathrm{U} / 1$, WBC $3,400 / \mathrm{mm}^{3}$, and $\operatorname{IgE~} 3,360 \mathrm{U} / 1$. His complaints continued thereafter. Two years before admission he developed vitiligo on the front of his head, which then spread widely to the arms and hands. Six months before admission slight fever and fatigability occurred. At that time, laboratory studies revealed a WBC of $4,300 / \mathrm{mm}^{3}$ with eosinophilia $\left(946 / \mathrm{mm}^{3}\right)$, and IgE of $3,700 \mathrm{U} / 1$. Five months before admission his vitiligo and erythema were improving with treatment with topical sunscreens and

From The Second Department of Internal Medicine, *Pathology and **Dermatology, Tokyo Medical and Dental University, Tokyo and $* * *$ The Department of Dermatology, Kyorin University, Tokyo Received for publication February 20, 1990; Accepted for publication October 2, 1990 Reprint requests should be addressed to Naoko Tojo, MD, Second Department of Internal Medicine, Tokyo Medical and Dental University, 1-5-45 Yushima, Bunkyo-ku, Tokyo 113, Japan 
topical corticosteroids. One month before admission he began having shortness of breath, and this condition gradually worsened. Ten days before admission he began to feel right dysphoria and dysbasia. $\mathrm{He}$ felt that he was suffering from a progressive illness.

On physical examination at admission, his temperature was $37.6^{\circ} \mathrm{C}$, pulse $108 / \mathrm{min}$ and regular, respiration $40 / \mathrm{min}$ and shallow, blood pressure was $122 / 78 \mathrm{mmHg}$. His face, neck, both arms, and the backs of both hands revealed rose-black erythema due to severe sunburn, clearly distinguished from normal areas that were shaded by his clothing. $\mathrm{He}$ had vitiligo on his frontal region, the dorsal aspect of both hands and lower part of both arms; on the hands, the areas surrounding the vitiligo were reddish (Fig. 1). There were some pigmented spots on his tongue and three red-to-violet nodular lesions on his left lower leg. Chest examination revealed bilateral basilar crackles. He showed right-side body agnosia and right constructive apraxia.

Laboratory studies revealed a hematocrit of $32.6 \%$, and a white blood cell count of $9,700 / \mathrm{mm}^{3}$ with $85 \%$ polymorphonuclear leukocytes, $11 \%$ lymphocytes $\left(1,067 / \mathrm{mm}^{3}\right), 0 \%$ eosinophils, $3 \%$ basophils, and $1 \%$ monocytes. The erythrocyte sedimentation rate was $109 \mathrm{~mm} / \mathrm{h}$, total protein 6.4 $\mathrm{g} / \mathrm{dl}$, with albumin $40.1 \%, \alpha_{1}$-globulin $6.2 \%$,

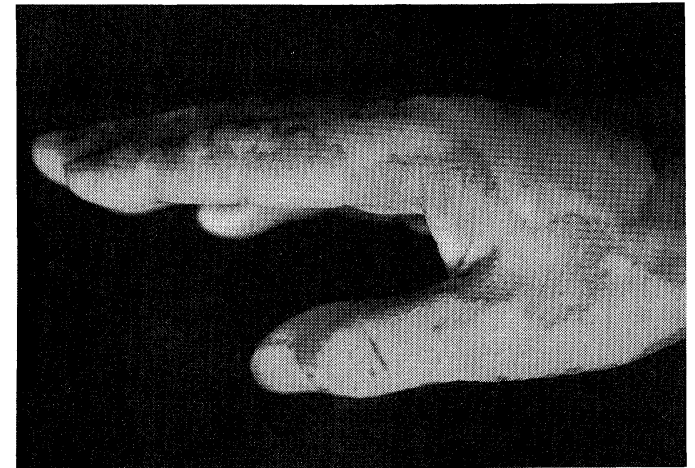

Fig. 1. Vitiligo appearing over the back of the patient's hands.

$\alpha_{2}$-globulin $13.7 \%, \beta$-globulin $15.2 \%$, and $\gamma$-globulin $24.0 \%$. IgG was $1,779 \mathrm{mg} / \mathrm{dl}$, IgM 98 $\mathrm{mg} / \mathrm{dl}, \operatorname{IgA} 687 \mathrm{mg} / \mathrm{dl}$, IgE 2,800 U/1. LDH was 952 U/1, GOT 29 U/1, GPT 13 U/1, $\gamma$-GTP 19 U/1. Antinuclear antibody was negative, $\mathrm{CH} 5035.3$ $\mathrm{CH} 50 \mathrm{U} / \mathrm{ml}$, direct Coombs test was negative. Arterial blood gas analysis showed pH 7.485, $\mathrm{Po}_{2}$ 50.0 Torr, $\mathrm{PcO}_{2} 31.2$ Torr, $\mathrm{HCO}_{3}^{-} 23.7 \mathrm{mEq} / \mathrm{l}$, and $\mathrm{BE} 1.7 \mathrm{mEq} / \mathrm{l}$ under room air. PPD skin test was negative. $\mathrm{CD} 4^{+} \mathrm{T}$ cell was $5.0 \%\left(39 / \mathrm{mm}^{3}\right)$ and the CD4/CD8 ratio was 0.08 , and serum anti-human immunodeficiency virus antibody was positive using the PA and Western blot method. Urinary porphyrin
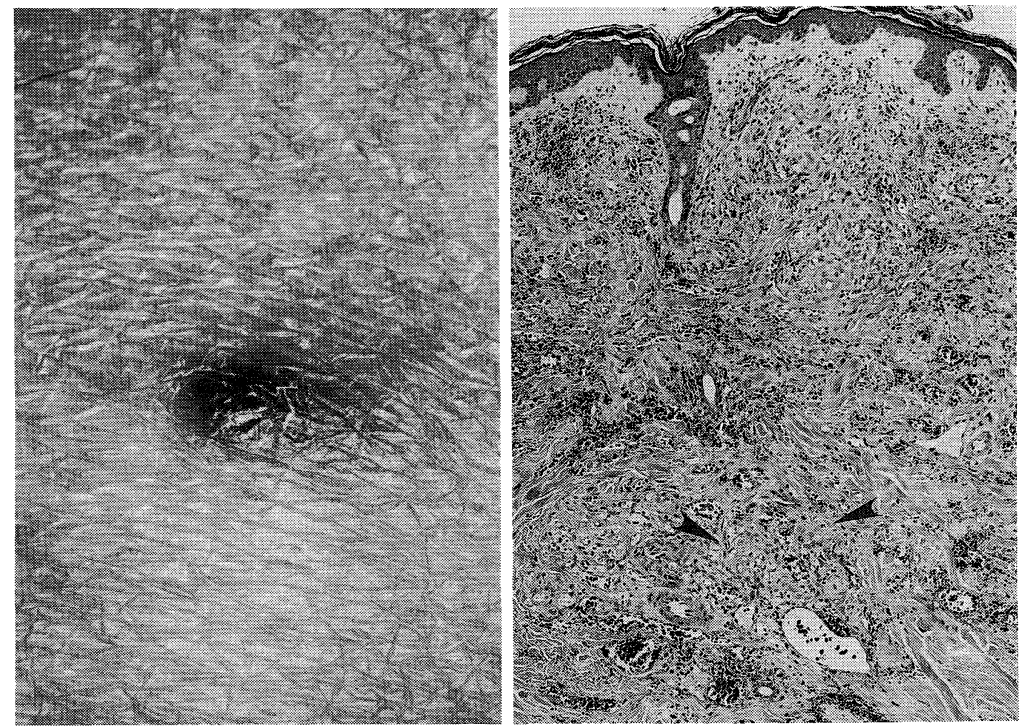

Fig. 2. a) (left) An early lesion of Kaposi's sarcoma: a red-to-violet nodule on the abdomen; b) (right) Biopsy specimen shows vascular proliferation and spindleshaped neoplastic cells (arrowheads) among a network of reticulin fibers (HE, $\times 100)$. 
precursors were within normal limits.

During his admission nodules and hyperpigmented maculae were widespread multiple redto-violet nodules; maculae appeared on his skin, including the extremities, chest, and abdomen (Fig. 2a). Biopsy of the new skin lesions revealed Kaposi's sarcoma (Fig. 2b). He also suffered from seborrheic dermatitis and oral and inguinal candidiasis $2 \mathrm{wk}$ after admission.

Because of the photodistribution of his rash, phototesting had been performed five months before

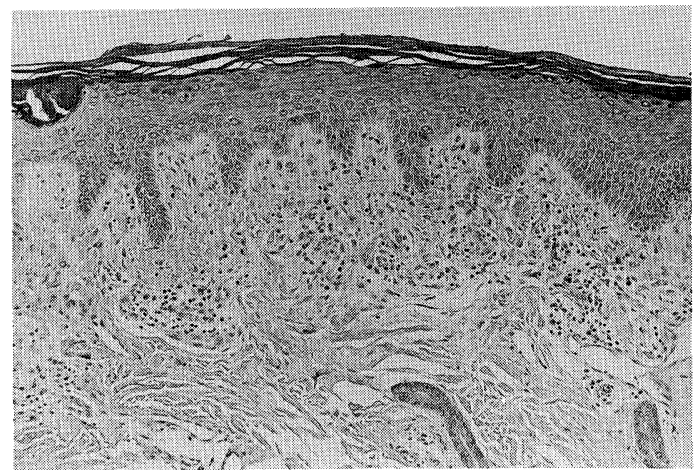

Fig. 3. Biopsy specimen from a vitiligo lesion shows mild acanthosis, reduced melanin granules in the epidermis, and perivascular lymphocytic infiltration in the upper dermis (HE, $\times 66)$. his admission. At that time he displayed photosensitivity to ultraviolet B (UVB, 290-320 nm) light. The minimal erythema dose to ultraviolet $\mathrm{A}$ (UVA) was $>8 \mathrm{~J} / \mathrm{cm}^{2}\left(\mathrm{~N},>8 \mathrm{~J} / \mathrm{cm}^{2}\right)$ and that to UVB was $30 \mathrm{~mJ} / \mathrm{cm}^{2}\left(\mathrm{~N},>100-200 \mathrm{~mJ} / \mathrm{cm}^{2}\right)$. His condition was diagnosed as chronic photosensitivity.

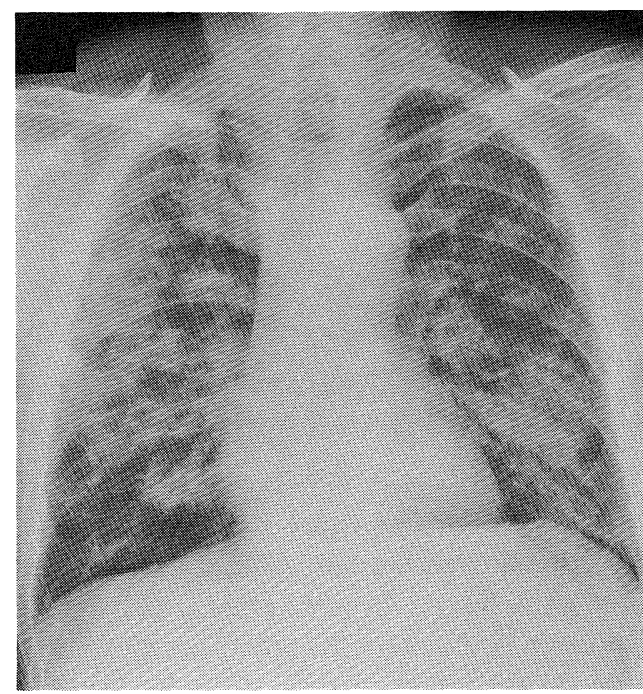

Fig. 4. Chest X-ray film on admission, showing diffuse reticular and patchy infiltration in both lung fields.
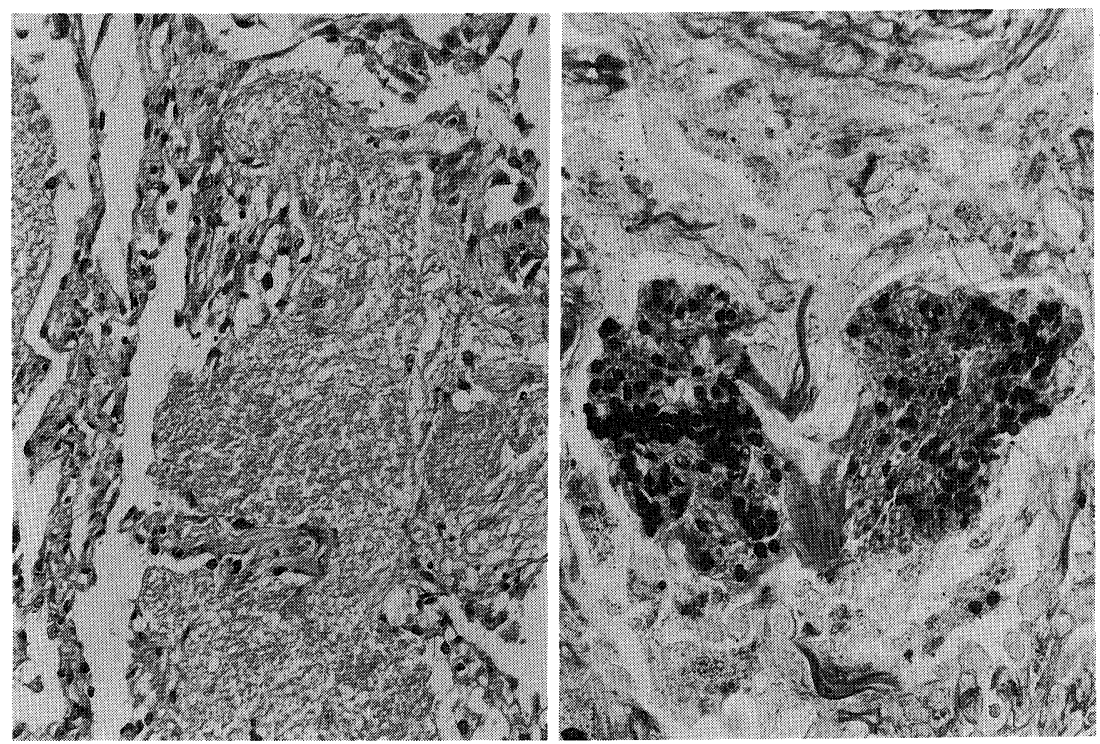

Fig. 5. a) (left) Transbronchial lung biopsy shows that the alveoli are filled with pink frothy honeycomb-like material $(\mathrm{HE}, \times 250)$; b) (right) Staining with methenamine silver demonstrates masses of organism (Grocott stain, $\times 420$ ) which was identified as pneumocystis carinii pneumonia. 


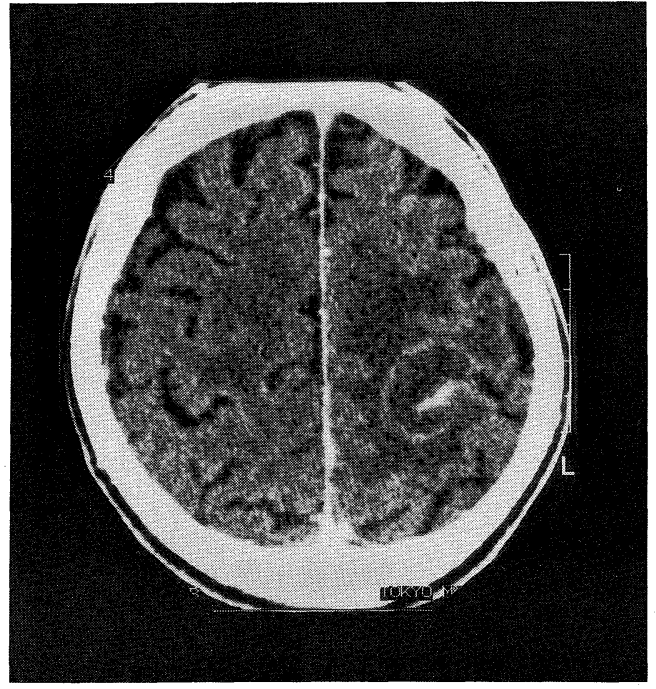

Fig. 6. Brain CT on admission, showing a ring-shaped enhanced mass with surrounding edema in the left parietal lobe.

Biopsy of a depigmented lesion five months before admission showed mild acanthosis, reduced melanin granules in the epidermis, exocytosis of lymphocytes, and mild perivascular lymphocytic infiltration in the upper dermis (Fig. 3). Immunohistochemical examinations of the biopsy specimen revealed that epidermal Langerhans cells were increased in number, and that the dermal infiltrates contained large numbers of $\mathrm{CD} 4^{+} \mathrm{T}$ cells, although there was a slight predominance of $\mathrm{CD} 8^{+} \mathrm{T}$ cells over $\mathrm{CD} 4^{+} \mathrm{T}$ cells.

A chest roentgenogram on admission revealed bilateral diffuse reticular and infiltrative shadows (Fig. 4), later diagnosed as pneumocystis carinii pneumonia by transbronchial lung biopsy (Fig. 5). He received trimethoprim-sulfamethoxazole (TMPSMX) and then appeared to be improving. However, he developed hyperkalemia, renal tubular acidosis, and renal failure, probably due to adverse effects from TMP-SMX. He then received aerosolized penthamidine, and recovered from the pneumonia, but not from the renal failure. Brain CT showed a left parietal ring-shaped enhanced mass (Fig. 6). It was suspected of being toxoplasmosis, and he was given acetylspiramycin together with glyceol and steroids. However, his consciousness became increasingly deteriorated and he died 56 days after admission due to brain herniation. A postmortem examination could not be conducted.

\section{DISCUSSION}

This case was diagnosed as AIDS by detection of anti-HIV antibody upon admission to our hospital. It is accordingly not clear whether he had already been infected with HIV when he began to note his cutaneous lesions. Nevertheless, it is certain that he became infected with HIV while staying in Zaire, because he had no other risk factors for HIV infection in Japan, including transfusions of blood components, drug abuse, or homosexual behavior. Furthermore, considering that HIV infection has a relatively long latent period, it is most probable that he had been already infected when he began to experience his symptoms.

A number of type of skin lesions have been reported in HIV infection (AIDS) (1-6). The cutaneous manifestations of HIV infection may be divided into three categories: neoplastic, infectious, and others. The present case had candidiasis, Kaposi's sarcoma, and seborrheic dermatitis. All of these are common among HIV-infected (AIDS) patients. On the contrary, vitiligo and chronic photosensitivity have been only rarely reported in association with HIV infection: vitiligo in only five cases (7), and photosensitivity in only one (8). The coincidence of these two cutaneous manifestations has not yet been reported. A relationship between HIV infection and the development of vitiligo has been previously described, but is not fully established yet. We rarely see new-onset vitiligo. There is some evidence for the association between vitiligo and certain immunological abnormalities. ChediakHigashi syndrome, characterized by parietal oculocutaneous albinism, has been related to impaired host defense mechanisms (9). The Vogt-KoyanagiHarada syndrome, characterized by bilateral uveitis associated with meningeal involvement, vitiligo, and dysacousia, has specific antibodies against surface antigens on normal melanocytes (10). Antimelanocyte antibodies have been noted in a substantial number of patients with chronic mucocutaneous candidiasis with vitiligo, but they are not detected in patients with common vitiligo (11).

The early phase of HIV infection may be accompanied by immunological abnormalities, characterized by lymphadenopathy, polyclonal B cell 
activation with hypergammaglobulinemia, and suppressor T cell (12) activation. If HIV infection and vitiligo are causally related, then polyclonal B cell activation with production of autoantibodies to melanocytes and/or cell-mediated cytotoxicity against melanocytes may contribute to the development of vitiligo. Otherwise, it is possible that melanocytes may be directly affected by HIV, since HIV usually involves the central nervous system (13) and melanocytes are derived from the neural crest. The immunohistochemical findings of a vitiligo lesion in the present case demonstrated the presence of lymphocytic infiltration composed of $\mathrm{CD} 4^{+}$and $\mathrm{CD}^{+} \mathrm{T}$ cells and an increase in number of Langerhans cells, whereas a previous report described the opposite findings (14). Patients with an advanced stage of HIV infection are usually deficient in helper $\mathrm{T}$ cells as well as HLA-DR-positive Langerhans cells in the skin. In this case, skin biopsy had been performed during the period of ARC, thus the pathological findings may differ from those of the previous report.

The basis for the association between photosensitivity and HIV infection in this case is not known. Most investigators agree that an immunologic reaction develops against a photoproduct derived from the interaction between light and a photoabsorbing substance. Wissel et al (15) reported three cases of porphilia associated with AIDS. This case, however, revealed neither porphyrin products nor a definable photosensitizer on admission. Our patient's symptoms appeared to be somewhat improved after AIDS evolved. In comparison with the period of ARC, his titer of IgE decreased from 3,700 $\mathrm{U} / 1$ to $2,800 \mathrm{U} / 1$, and the number of eosinophils decreased from $946 / \mathrm{mm}^{3}$ to $0 / \mathrm{mm}^{3}$ during the period of AIDS. Thus, the status of immunological activation in the early phase of HIV infection in this case may have contributed to the development of chronic photosensitivity.

This is a very rare case of vitiligo and photosensitivity associated with HIV infection. Although the role of HIV infection in these two skin lesions is not clear, the immunological responses that occur early in the course of HIV infection may contribute to the development of both of these skin lesions.

\section{REFERENCES}

1) Fisher BK, Warner LC. Cutaneous manifestations of the acquired immunodeficiency syndrome. Int $\mathrm{J}$ Dermatol 26: 615, 1987.

2) Kaplan MH, Sadick N, McNutt NS, Melzer M, Sarngaharan MG, Pahwa S. Dermatologic findings and manifestation of acquired immunodeficiency syndrome (AIDS). J Am Acad Dermatol 16: 485, 1987.

3) Penney NS, Hicks B. Unusual cutaneous lesion associated with acquired immunodeficiency syndrome. J Am Acad Dermatol 13: 845, 1985.

4) Mathes BM, Douglass MC. Seborrheic dermatitis in patients with acquired immunodeficiency syndrome. $\mathbf{J}$ Am Acad Dermatol 13: 947, 1985.

5) Warner BM, Fisher BK. Cutaneous manifestation of the acquired immunodeficiency syndrome. Int $\mathbf{J}$ Dermatol 25: 337, 1986.

6) Hara SK, Wadhawan D, Kamanga J, et al. Cutaneous manifestations of human immunodeficiency virus in Lusaka, Sambia. J Am Acad Dermatol 19: 451, 1988.

7) Duvic M, Rapini R, Hoots WK, Mansell PW. Human immunodeficiency virus-associated vitiligo: Expression of autoimmunity with immunodeficiency? J Am Acad Dermatol 17: 656, 1987.

8) Toback AC, Longley J, Cardullo AC, Doddy 'U, Ramangnoli M, DeLeo VA. Severe chronic photosensitivity in association with acquired immunodeficiency syndrome. J Am Acad Dermatol 15: 1056 , 1986.

9) Clark RA, Root RK, Kimbell HR. The Chediak-Higashi syndrome: Studies of host defenses. Ann Intern Med 76: 293, 1972.

10) Tagawa Y, Sugiura K. Antibody-dependent cellmediated cytotoxicity (ADCC) against melanocyte antigens in Vogt-Koyanagi-Harada syndrome. Jpn J Ophthalmol 81: 177, 1979.

11) Howanitz N, Nordlund JJ, Lerner AB, Bystryn JC. Autoantibodies to melanocytes. Arch Dermatol 117: 705, 1981.

12) DeVita VT, Hellman S, Rosenberg SA. AIDS, Lippincott Press, Philadelphia, 1988, p.61.

13) Koenig S, Gendelman HE, Orenstein JM, et al. Detection of AIDS patients with encephalopathy. Science 233: 1089, 1986.

14) Belsito DV, Sanchez NR, Baer RL, et al. Reduced Langerhans cell Ia antigen and ATPase activity with the acquired immunodeficiency syndrome. N Engl J Med 310: 1279, 1984.

15) Wissel PS, Sordillo P, Anderson KE, Sassa S, Savillo RL, Kappas A. Porphyria cutanea tarda associated with the acquired immunodeficiency syndrome. Am J Hematol 25: 107, 1987. 